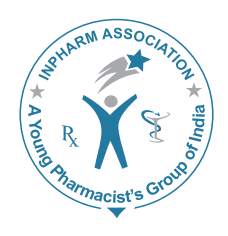

\title{
JVP
}

\section{Dissofilm: A Novel Approach for Delivery of Phenobarbital; Design and Characterization}

\author{
Yellanki SK, Jagtap S ${ }^{1}$, Masareddy $\mathbf{R}^{1}$ \\ Department of Pharmaceutics, Ganga Pharmacy College, Nizamabad, Andhra Pradesh, \\ ${ }^{1} J$. N. Medical College, KLE University, Belgaum, Karnataka, India \\ Address for correspondence: Dr. Yellanki SK; E-mail: shivakmr19842@gmail.com
}

\begin{abstract}
An attempt to develop and evaluate mouth-dissolving film of phenobarbital for quick effect in treatment of epilepsy occurring in pediatric population has been made in the present study. Suitable film formers and plasticizers are selected based on optimization studies. Effect of superdisintegrants in formulation of mouth dissolving films at different concentrations has been investigated. Films were prepared by solvent casting method. The prepared films were evaluated for physicochemical parameters, in vitro disintegration and dissolution time, in vitro release rate study, stability study, and in vivo animal safety study. The best formulation was found to be F3 showing $96.57 \%$ drug release in $14 \mathrm{~min}$, following first-order kinetics. X-Ray diffraction studies show change in crystalline nature of drug in formulation. In vivo studies in hamster reports effective and safe use of formulation in animals.
\end{abstract}

Key words: Hydroxypropylmethyl cellulose, mouth-dissolving film, phenobarbital, sodium starch glycolate, X-ray diffraction

\section{INTRODUCTION}

Rapidly dissolving films (RDFs) have recently gained popularity in the form of breath fresheners. These films are placed in the mouth and dissolve quickly to release the flavor. Rapidly dissolvable films were developed on the technology of transdermal patch. RDFs are already being used in breath-freshening products from Warner Lambert and Wrigley's in the US and Europe. Zengen recently launched a chloraseptic relief strip in the US to

\begin{tabular}{|l|l|}
\hline \multicolumn{2}{|c|}{ Access this article online } \\
\hline Quick Response Code: & \\
\hline & Website: \\
\hline & www.jyoungpharm.in \\
& \\
\hline
\end{tabular}

Journal of Young Pharmacists Vol 3 / No 3 deliver benzocaine-a local anesthetic to treat sore throats. This delivery system is simply placed on a patient's tongue or any oral mucosal tissue. Instantly wet by saliva, the film rapidly hydrates and adheres onto the site of application. It then rapidly disintegrates and dissolves to release the medicament for mucosal absorption or, with modifications, allows oral gastrointestinal absorption with a quickdissolving aspect. ${ }^{[1]}$

Advantages of rapidly dissolving films

- Ease of administration to patients who cannot swallow, such as the elderly, stroke victims and bedridden patients; patients who should not swallow, such as renal failure patients; and who refuse to swallow, such as pediatrics, geriatric, and psychiatric patients.

- Patient's compliance for disabled bedridden patients and for traveling and busy people who do not have 
ready access to water.

- More rapid drug absorption from the pregastric area, i.e., mouth, pharynx, and oesophagus which may produce rapid onset of action.

- Pregastric absorption can result in improved bioavailability, reduced dose, and improved clinical performance by reducing side effects.

Epilepsy is a chronic condition characterized by the repeated attacks of epileptic seizures. Epileptic seizures can occur in nonepileptic patients subjected to a variety of stresses and stimuli. Epileptic seizures differ from other types of paroxysmal attacks by their clinical expression and by their mechanism. The epileptic seizures and paroxysmal attacks are expressed on the electroencephalogram by the epileptic discharge. ${ }^{[2]}$

Phenobarbital, the longest-acting barbiturate, is used for its anticonvulsant and sedative-hypnotic properties in the management of all seizure disorders except absence. Absorbed in varying degrees following oral, rectal or parenteral administration. The salts are more rapidly absorbed than are the acids. The rate of absorption is increased if the sodium salt is ingested as a dilute solution or taken on an empty stomach. Phenobarbitone is the clinically effective anticonvulsant enhances the inhibitory effect of gamma aminobutyric acid (GABA) by facilitating the GABA-medicated opening of chloride channels. ${ }^{[3]}$

An attempt was made in the present investigation to prepare fast dissolving drug delivery systems of phenobarbital by solvent-casting method for rapid therapy of epileptic seizures.

\section{MATERIALS AND METHODS}

\section{Materials}

Phenobarbital was a gift sample obtained from AngloFrench Drugs and Industries Ltd, Bangalore, India. Methocel - E 15, E 50 obtained from Dow Chemical Company, Mirland. Pectin and Pullulan were obtained from Lipoid GmbH, Germany. Hydroxypropyl cellulose, Gelatin, Xanthan Gum, Propylene Glycol and Aspartame were obtained from S.D. Fine-Chem Ltd., Mumbai, India. Sodium Starch Glycolate and Croscarmellose Sodium were obtained from DMV - Fonterra Excipients, Netherlands. INDION-414 was obtained from Ion Exchange India Ltd., Ankaleshwar, India. Other chemicals used were of analytical grade and procured from S.D. Fine Chemicals (Mumbai, India). Concentrations of Phenobarbital were measured with a UV-VIS spectrometer (UV-1700,
Shimadzu Corporation, Tokyo, Japan). Interaction between Phenobarbital and polymers was verified using FTIR and TLC techniques.

Optimization of the components for formulation of placebo fast dissolving films

The placebo films were prepared by solvent-casting method. Hydroxypropylmethyl cellulose (HPMC) is known for its good film forming properties and has excellent acceptability. Hence, HPMC namely Methocel E15 was evaluated to optimize the effective concentration keeping the other components of the formulations to a constant mean value. Similarly an identical approach was used to optimize the other components such as secondary film modifier (pectin), film modifier (Xanthan gum) and plasticizer (propylene glycol) using the previously optimized concentration of respective components. The general method for preparation of placebo film is as follows. Previously primary film former, secondary film formers and film modifiers were soaked in water for $4 \mathrm{~h}$ and then uniformly dispersed to obtain dispersion. Aspartame and plasticizers were uniformly dissolved in $5 \mathrm{ml}$ of 95\% (v/v) ethanol. Alcoholic solution and the polymeric dispersion were mixed to obtain a homogenous dispersion. Ten milliliters of the dispersion was cast onto each petri dish which was lubricated with olive oil. The dispersion was dried in a hot air oven at $40-45^{\circ} \mathrm{C}$. The films were carefully removed from petri dishes and cut into strips of dimensions $3 \times 3 \mathrm{~cm}$ and stored in an air tight glass bottle. The films were evaluated for imperfections and cuts, mechanical strength, thickness, and dissolution time. ${ }^{[4]}$

Preparation of the phenobarbital containing fast dissolving films

Phenobarbital (PBT) containing fast dissolving films were fabricated as per the method described for the fabrication of blank fast dissolving films. PBT was incorporated in $5 \mathrm{ml}$ of $95 \%(\mathrm{w} / \mathrm{v})$ ethanolic solution and the rest of the procedure was same as that for the fabrication of blank fast dissolving films. Superdisintegrants (sodium starch glycolate or croscarmellose sodium) was uniformly dispersed in aqueous dispersion. The compositions of PBT containing films are shown in Table 1.

Evaluation of formulated mouth dissolving films

Film thickness

Thickness of films was measured using calibrated dial caliper. ${ }^{[4]}$

Weight variation

The study was carried out on ten films obtained from 
Table 1: Compositions of phenobarbital mouth-dissolving films

\begin{tabular}{lccccccc}
\hline Ingredients & F1 & F2 & F3 & F4 & F5 & F6 & F7 \\
\hline Phenobarbital & 117 & 117 & 117 & 117 & 117 & 117 & 117 \\
METHOCEL- E 15 & 150 & 150 & 150 & 150 & 150 & 150 & 150 \\
Pectin & 50 & 50 & 50 & 50 & 50 & 50 & 50 \\
HPC (low viscosity grade) & 25 & 25 & 25 & 25 & 25 & 25 & 25 \\
Menthol & 40 & 40 & 40 & 40 & 40 & 40 & 40 \\
Aspartame & 3 & 3 & 3 & 3 & 3 & 3 & 3 \\
Glycerol & 125 & 125 & 125 & 125 & 125 & 125 & 125 \\
Xanthan gum & 10 & 10 & 10 & 10 & 10 & 10 & 10 \\
Sodium starch glycolate & - & 50 & 100 & 150 & - & - & - \\
Croscarmellose sodium & - & - & - & - & 50 & 100 & 150 \\
Propylene glycol & 100 & 100 & 100 & 100 & 100 & 100 & 100 \\
Water & 5 & 5 & 5 & 5 & 5 & 5 & 5 \\
Ethanol & 7 & 7 & 7 & 7 & 7 & 7 & 7 \\
\hline
\end{tabular}

All the weights are taken in $\mathrm{mg}$, except water and ethanol taken in $\mathrm{ml}$

each formulation batch. The mean weight of film as well as the deviation from the mean was calculated and recorded..$^{[5]}$

\section{Hydration study (water uptake/swelling study)}

The film sample was weighed and placed on a preweighed stainless steel wire mesh. The wire mesh was then submerged in a petridish containing $20 \mathrm{ml}$ distilled water. Increase in weight of the film was determined at regular time intervals until a constant weight was obtained. ${ }^{[6,7]}$

The hydration ratio of the film was calculated using following formula:

$\%$ Hydration ratio $=\frac{\mathrm{W}_{\mathrm{t}}-\mathrm{W}_{\mathrm{o}}}{\mathrm{W}_{\mathrm{o}}} \times 100$,

where $\mathrm{W}_{\mathrm{t}}=$ weight of film at time $\mathrm{t}$ and $\mathrm{W}_{\mathrm{o}}=$ weight of film at zero time.

\section{Moisture loss (moisture vapor transmission)}

The percent moisture loss was determined by placing prepared film in desiccators containing anhydrous calcium chloride. After three days, the film was taken and reweighed. The percent moisture loss was calculated using following formula: ${ }^{[8,9]}$

Moisture loss $(\%)=\frac{W_{o}-W_{t}}{W_{o}} \times 100$,

where $\mathrm{W}_{\mathrm{o}}=$ initial weight and $\mathrm{W}_{\mathrm{t}}=$ final weight.

\section{Percent elongation at break}

The prepared film was pulled by means of a pulley system. ${ }^{[10]}$ Weights were gradually added to the pan to increase the pulling force till the film was broken. The elongation was determined by noting the distance traveled by pointer before break of film on the graph paper. The percent elongation at break was calculated by using formula:
Percent elongation at break $\left(\mathrm{mm}^{-2}\right)$

$=\frac{\mathrm{L}_{1}}{\mathrm{~L}_{\mathrm{o}}} \times \frac{100}{\text { cross }- \text { sectional area }}$,

where $\mathrm{L}_{1}=$ increase in the length, $\mathrm{L}_{\mathrm{o}}=$ initial length.

Tensile strength

Film strip of dimension $5 \times 2 \mathrm{~cm}^{2}$ and free from air bubbles or physical imperfections was held between two clamps positioned at a distance of $3 \mathrm{~cm}$ apart. A cardboard was attached on the surface of the clamp via a double sided tape to prevent the film from being cut by the grooves of the clamp. During measurement, the strips were pulled at the bottom clamp by adding weights in pan till the film breaks. The force was measured when the films broke. Results from film samples, which broke at and not between the clamps were not included in calculations: $:^{[1]}$

Tensile strength $\left(\mathrm{kg} / \mathrm{mm}^{2}\right)$

$=\frac{\text { Breaking force }(\mathrm{F})}{\text { Cross-sectional area of sample }(\mathrm{A})}$

\section{Folding endurance}

This parameter was determined by repeatedly folding one film at the same place till it broke. The number of times the film could be folded at the same place without breaking/ cracking give the value of folding endurance. ${ }^{[8,9]}$

\section{Drug content and content uniformity}

The drug content and content uniformity test was performed to ensure uniform and distribution of drug. $3 \mathrm{~cm}^{2}$ films was cut, weighed and dissolved in $100 \mathrm{ml}$ methanol. Three milliliters of supernatant aqueous solution was withdrawn and transferred in $100 \mathrm{ml}$ volumetric flask. Final dilution up to mark was done using simulated saliva and analyzed spectroscopically at $254 \mathrm{~nm}$ wavelength. The concentration of phenobarbital (in $\mu \mathrm{g} / \mathrm{ml}$ ) was calculated by using standard calibration curve of phenobarbital. Content uniformity of phenobarbital films were done by selecting randomly five $3 \mathrm{~cm}^{2}$ films from different batches and performing study same as drug content. ${ }^{[4]}$

\section{In vitro disintegration and dissolution time}

The disintegration time is the time when a film starts to break or disintegrate. The dissolution time is the time when the film completely dissolves. The in vitro disintegration and dissolution time of fast-dissolving films was determined visually in a glass dish of $25 \mathrm{ml}$ distilled water with swirling every $10 \mathrm{~s}$. Disintegration and dissolution time was measured. ${ }^{[4]}$

In vitro dissolution study (drug release rate study)

The in vitro dissolution test was carried out in USP basket type 
apparatus. ${ }^{[12,13]}$ Samples of PBT-loaded films were equivalently containing $15 \mathrm{mg}\left(3 \mathrm{~cm}^{2}\right)$ was cut and placed basket. The dissolution medium consisted of $500 \mathrm{ml}$ freshly deionized simulated saliva ( $\mathrm{pH}$ 6.8), maintained at $37 \pm 1^{\circ} \mathrm{C}$ and stirred at $100 \mathrm{r} / \mathrm{min}$. Samples of $1 \mathrm{ml}$ were withdrawn at predetermined time intervals and replaced with fresh medium. The samples were filtered through Whatman filter paper and PBT concentrations were assayed spectrophotometrically at 254 $\mathrm{nm}$ after final appropriate dilution.

The dissolution profile of conventional marketed tablet LUMINAL ${ }^{\circledR}$ containing $15 \mathrm{~g}$ equivalent phenobarbital was also determined using same experimental setup.

\section{Surface morphology study using scanning electron microscopy} The surface morphology of formulated PBT film was assessed using a scanning electron microscope. Samples were mounted on round brass stubs (12 $\mathrm{mm}$ diameter) using double-backed adhesive tape and then sputter coated for 8 min under argon atmosphere with gold before examination under the scanning electron microscope. Pictures were then taken at an excitation voltage of $15 \mathrm{kV} .^{[9]}$

\section{Stability studies}

Stability tests are the series of tests designed to obtain information on the stability of the pharmaceutical product in order to define its shelf life and utilization period under specified packaging and storage conditions.

From the seven batches of PBT films, optimized formulation was tested for stability studies. Films of optimized formula were stored at two different storage conditions namely $30^{\circ} \mathrm{C} \pm 0.5 / 60 \pm 1 \% \mathrm{RH}$ and $40^{\circ} \mathrm{C} \pm 0.5 / 75 \pm 1 \% \mathrm{RH}$. Each film was wrapped in a butter paper followed by aluminium foil and placed in an aluminium pouch, which was heat-sealed at the end. The films were evaluated for weight, PBT content and in vitro drug release after storage for 10, 20, and 30 days. The values for in vitro PBT release from the films were calculated and were compared for change in the dissolution profile. ${ }^{[4]}$

\section{In-vivo animal safety study (irritation study)}

The in vivo animal safety study is carried out to find safety of films in oral cavity. Hamster cheek pouch was selected as model for study. ${ }^{[14]}$

Either sex of Hamster of 100-150 g was selected for study. They were housed individually in an environmentally controlled room with $12 \mathrm{~h}$ light/dark cycle and had free access to food and water. After 7 days acclimatization period, they were randomly selected for different experimental groups.
All the experimental procedures were carried out in accordance with committee for the purpose of control and supervision of experiments on animal (CPCSEA) guidelines. The study was reviewed and approved by the Institutional Animal Ethics Committee (JNMC/IAEC/2/28/2008). J.N. Medical College, KLE University, Belgaum, India.

Experimental study design in hamsters

Group: I Normal or placebo film treated group.

Group: II PBT film treated group.

The placebo or PBT film was placed twice a day for 4-5 consecutive days. The prepared PBT film sample was placed in cheek pouch of hamster for $10 \mathrm{~min}$ and then rinsed using distilled water. Then pouch was observed for any adverse effects (irritation), redness immediately and after $24 \mathrm{~h}$ interval.

\section{RESULTS AND DISCUSSION}

\section{Thickness}

The thicknesses of formulated films were found to be in range of $13.76 \pm 0.539$ to $14.3334 \pm 0.0506 \mathrm{~mm}$. The mean values are tabulated in Table 2 . The values are almost uniform in all formulations. Obtained results has shown that increase in film thickness decreases tensile strength while increases $\%$ elongation. Further increases in thickness of film increases crystallinity of film and decrease dissolution rate.

\section{Weight variation test}

The percentage weight variation for all the formulation is tabulated in Table 2. All the films passed weight variation test as the $\%$ weight variation was within the pharmacopoeial limits of $\pm 7.5 \%$. It was found to be in range of $110.2 \pm 0.20$ to $127.2 \pm 0.30 \mathrm{mg}$. The weight of all the films was found to be uniform.

\section{Hydration study (water uptake/swelling study)}

The hydration ratio defines the ability of films to absorb water from environment or from dissolution media. It is also termed as water uptake study. Hydration ratio gives an idea of films dissolution time and disintegration time. Higher values of hydration ratio indicate that films dissolve faster and easily. Hydration ratio values of all formulation are shown in Table 2. Increase in concentration of superdisintegrant increases hydration ratio or water uptake and decrease disintegration and dissolution time. F3 and F6 formulations showed higher hydration ratio while F1 formulation shows low hydration ratio. 
Yellanki, et al:: Dissofilm: A novel approach for delivery of phenobarbital

Table 2: Thickness, mean weight (mg), drug content (mg), \%hydration ratio, \%moisture loss of mouth dissolving films of phenobarbital

\begin{tabular}{lccccc}
\hline Formulation & Thickness & Mean weight $(\mathrm{mg})^{\mathrm{a}}$ & ${\text { Drug content }(\mathrm{mg})^{\mathrm{b}}}$ & \% Hydration ratio $^{\mathrm{a}}$ & \% Moisture loss $^{\mathrm{a}}$ \\
\hline F1 & $13.9166 \pm 0.045$ & $110.2 \pm 0.20$ & $13.65 \pm 0.05$ & $0.808 \pm 0.004$ & $2.995 \pm 0.002$ \\
F2 & $14.3054 \pm 0.0986$ & $117.3 \pm 0.25$ & $16.29 \pm 0.076$ & $0.727 \pm 0.003$ & $1.024 \pm 0.004$ \\
F3 & $14.22 \pm 0.0239$ & $121.8 \pm 0.95$ & $18.71 \pm 0.26$ & $0.616 \pm 0.002$ & $1.426 \pm 0.005$ \\
F4 & $13.76 \pm 0.539$ & $119.3 \pm 0.30$ & $17.13 \pm 0.13$ & $0.518 \pm 0.005$ & $1.973 \pm 0.003$ \\
F5 & $13.9722 \pm 0.050$ & $127.2 \pm 0.30$ & $14.50 \pm 0.076$ & $0.701 \pm 0.001$ & $2.203 \pm 0.003$ \\
F6 & $14.3334 \pm 0.050$ & $123.6 \pm 0.20$ & $19.75 \pm 0.17$ & $0.505 \pm 0.001$ & $2.346 \pm 0.001$ \\
F7 & $14.1388 \pm 0.0326$ & $119.1 \pm 0.20$ & $13.92 \pm 0.047$ & $0.462 \pm 0.007$ & $2.016 \pm 0.002$ \\
\hline
\end{tabular}

a Significance value $P>0.0001$, bignificance value $P>0.001, n=$ average of triplicate was determined

Moisture loss (moisture vapor transmission)

MVT is defined as the quantity of moisture transmitted through unit area of film in unit time. The moisture loss study gives an idea about films stability nature and ability of films to withstand its physicochemical properties under normal conditions. It also gives idea about hydrophilicity of film formulations. The obtained results are tabulated in Table 2. The obtained values are almost uniform and ranges from $1.024 \pm 0.004 \%$ to $2.995 \pm 0.002 \%$. F1, F5, and F6 formulation showed high \% moisture loss while F2 and F3 formulations showed low $\%$ moisture loss.

Tensile strength

The tensile testing gives an indication of the strength and elasticity of the film, reflected by the parameters, tensile strength (TS), elastic modulus (EM) and elongation at break (E/B). A soft and weak polymer is characterized by a low TS, EM, and E/B; a hard and brittle polymer is defined by a moderate TS, high EM and low E/B; a soft and tough polymer is characterized by a moderate TS, low $\mathrm{EM}$ and high E/B; whereas a hard and tough polymer is characterized by a high TS, EM and E/B. Tensile strength of all prepared formulation is shown in Table 3. Results revealed that formulations showed better tensile strength and less to moderate $\%$ elongation.

Tensile strength was found in range of $0.462 \pm 0.007$ to $0.808 \pm 0.004 \mathrm{~kg} / \mathrm{mm}^{2}$. There is no significant change in the tensile strength of all formulations. Addition of superdisintegrants (SD) affects tensile strength and also \% elongation. An optimum concentration of superdisintegrant showed improvement of tensile strength, but at higher concentration there was no further increase in tensile strength. Higher concentration of superdisintegrant increases thickness and crystallinity of films which causes decrease in tensile strength as well as percent elongation.

\section{Percent elongation}

Percent elongation is mainly based on tensile strength of films. The nature of polymers affects tensile strength and $\%$ elongation. Soft and brittle polymer increases tensile strength and decreases \% elongation while hard and tough polymer increases tensile strength as well as \% elongation. \% Elongation of all formulation is tabulated in Table 3. The values of $\%$ elongation are in range of $4.108 \pm 0.001 \%$ to $6.143 \pm 0.001 \%$. Increase in concentration of superdisintegrant decreases $\%$ elongation which indicates that elasticity and softness of film decreases which helps in fast dissolution of films.

\section{Folding endurance}

Folding endurance measures the ability of patch to withstand rupture, higher the folding endurance lower will be chances of film to rupture easily and vice versa. The folding endurance of all formulations is tabulated in Table 3. Increase in concentration of superdisintegrants increases folding endurance of films but after specific concentration increase in concentration of superdisintegrants decreases folding endurance. This was due to increase in crystallinity of film and also film thickness. More the thickness of lower will be folding endurance. F3 and F6 formulation showed high folding endurance $55.67 \pm 1.15$ and $46.33 \pm 0.57$, respectively.

Drug content and content uniformity study

The drug content and content uniformity test was performed to ensure uniform and accurate distribution of drug. The content uniformity was performed for all the seven formulations and results are tabulated in Table 2. Five trials from each formulation were analyzed spectrophotometrically. The mean value and standard deviation of all the formulations were calculated. The results indicated that in all the formulations the drug content was uniform. The cumulative percentage drug released by each film to the in vitro release studies was based on the mean content of the drug present in the respective film.

\section{In vitro disintegration time dissolution time test}

The disintegration time is the time when a film starts to break or disintegrate. The dissolution time is the time when 
Yellanki, et al:: Dissofilm: A novel approach for delivery of phenobarbital

Table 3: Tensile strength, \%elongation, folding endurance, disintegration time, dissolution time of mouth-dissolving films of phenobarbital

\begin{tabular}{|c|c|c|c|c|c|}
\hline Formulation & Tensile strength $^{\mathrm{a}} \mathrm{kg} / \mathrm{mm}^{2}$ & $\%$ Elongation ${ }^{a}$ at break & Folding endurance $^{\mathrm{a}}$ & Disintegration time $^{a}$ (s) & ${\text { Dissolution time }{ }^{\mathrm{a}}(\mathrm{s})}$ \\
\hline$\overline{\mathrm{F} 1}$ & $0.808 \pm 0.004$ & $6.143 \pm 0.001$ & $45 \pm 1$ & $31.33 \pm 0.577$ & $126 \pm 0.58$ \\
\hline $\mathrm{F} 2$ & $0.727 \pm 0.003$ & $5.144 \pm 0.001$ & $50 \pm 2$ & $27 \pm 1.00$ & $94.00 \pm 1.0$ \\
\hline F3 & $0.616 \pm 0.002$ & $5.132 \pm 0.001$ & $55.67 \pm 1.1$ & $23.33 \pm 1.155$ & $73.67 \pm 1.528$ \\
\hline $\mathrm{F} 4$ & $0.518 \pm 0.005$ & $4.114 \pm 0.001$ & $44.00 \pm 2$ & $23.33 \pm 1.00$ & $72.33 \pm 1.528$ \\
\hline F5 & $0.701 \pm 0.001$ & $5.141 \pm 0.001$ & $40.67 \pm 0.57$ & $28 \pm 1.00$ & $99.33 \pm 1.528$ \\
\hline F6 & $0.505 \pm 0.001$ & $4.118 \pm 0.001$ & $46.33 \pm 0.57$ & $26 \pm 0.577$ & $79.33 \pm 1.528$ \\
\hline F7 & $0.462 \pm 0.007$ & $4.108 \pm 0.001$ & $37.67 \pm 0.57$ & $24.33 \pm 1.155$ & $76.00 \pm 2.0$ \\
\hline
\end{tabular}

a: significance value $P>0.0001, n=$ Average of triplicate was determined

the film completely dissolves. Disintegration time and dissolution time of formulated films is tabulated in Table 3. Results revealed that addition of superdisintegrants decreases the disintegration time and dissolution time. Disintegration time and dissolution time of all formulation were in range of $23.33 \pm 1.00$ to $31.33 \pm 0.577 \mathrm{~s}$ and $72.33 \pm 1.528$ to $126 \pm 0.58 \mathrm{~s}$, respectively.

In vitro dissolution study (drug release rate study)

Cumulative drug release and cumulative \% drug retained were calculated on the basis of drug content of phenobarbital present in the respective film. The results obtained in the in vitro drug release for the formulations F1 to $\mathrm{F} 7$ and marketed tablet "LUMINAL" ${ }^{\mathbb{B}}$ " is tabulated in Table 4. The plots are depicted in Figure 1 ( $a$ and $b$ ) for $\%$ cumulative drug release versus time. Formulation F1, F2, F3, shows drug release up to $87.836 \%, 89.282 \%, 96.574 \%$, respectively, at end of $14 \mathrm{~min}$. Rapid drug dissolution was observed in F4, F5, F6, and F7 which release $96.307 \%$, $88.442 \%, 93.735 \%$, and $95.114 \%$, respectively, at end of 14 min. F3 formulation shows highest percent of drug release $(96.574 \%)$ than other formulations. The observed rapid dissolution might be due to fast disintegration of films and rapid dissolution of drug. Increase in the concentration of superdisintegrants increases dissolution rate of drug which was observed in F3, F4, F6 formulation, but further increase in concentration of superdisintegrants will not increases dissolution rate much more which was observed in film F4, F7. Also increase in the concentration of superdisintegrants causes precipitation of films and decreases tensile strength and folding endurance. This is observed at concentration of $\geq 2 \%$ of the film. The drug release was completely achieved in a shorter duration of time. In vitro release rate study of $\mathrm{F} 3$ formulation vs. conventional marketed tablet LUMINAL ${ }^{\circledR}$ containing $15 \mathrm{mg}$ phenobarbital has shown that F3 release found to be faster and complete within $15 \mathrm{~min}$. In vitro release of LUMINAL ${ }^{\circledR}$ was found to be $15 \%$ in 14 min and up to $46 \%$ at half an hour. The correlation coefficient values obtained are shown
Table 4: In vitro release profile of phenobarbital mouth dissolving film formulations

\begin{tabular}{lcccccccc}
\hline \multirow{2}{*}{$\begin{array}{l}\text { Time } \\
\text { (min) }\end{array}$} & \multicolumn{7}{c}{ Cumulative \% drug released } \\
\hline 1 & 16.781 & 18.935 & 23.117 & 22.672 & 17.648 & 20.592 & 21.668 & 0.264 \\
2 & 28.420 & 29.225 & 37.169 & 35.966 & 27.640 & 27.744 & 33.679 & 0.794 \\
3 & 40.257 & 39.181 & 47.094 & 46.891 & 37.553 & 33.631 & 45.624 & 1.591 \\
4 & 47.997 & 45.665 & 55.892 & 55.974 & 45.648 & 41.376 & 54.993 & 2.393 \\
5 & 56.048 & 54.404 & 66.182 & 65.513 & 53.921 & 49.814 & 64.147 & 3.463 \\
6 & 66.290 & 67.891 & 76.921 & 70.759 & 64.645 & 60.643 & 73.747 & 4.407 \\
7 & 72.022 & 74.791 & 84.697 & 84.721 & 72.886 & 67.230 & 78.642 & 5.488 \\
8 & 77.785 & 78.333 & 90.806 & 89.120 & 79.434 & 77.632 & 88.187 & 6.707 \\
9 & 80.355 & 83.329 & 92.349 & 91.233 & 83.475 & 83.006 & 91.175 & 7.932 \\
10 & 82.937 & 84.563 & 93.636 & 92.404 & 84.595 & 87.496 & 92.196 & 9.165 \\
11 & 84.054 & 86.062 & 94.401 & 93.307 & 85.719 & 90.444 & 93.088 & 10.932 \\
12 & 85.578 & 87.045 & 95.168 & 94.621 & 86.847 & 91.451 & 93.850 & 12.312 \\
13 & 86.839 & 88.162 & 95.805 & 95.39 & 87.577 & 92.461 & 94.614 & 13.700 \\
14 & 87.836 & 89.282 & 96.574 & 96.307 & 88.442 & 93.735 & 95.114 & 14.831 \\
\hline
\end{tabular}

in Table 5. The results were found to be linear for firstorder release. It is concluded that release of drug from formulations F1-F7 followed first order.

Surface morphology study using scanning electron microscopy

SEM was performed on the films to assess changes in their surface morphology prior to and after dissolution testing and is depicted in Figure $2(\mathrm{a}-\mathrm{c})$. A smooth and compact surface with crystals of phenobarbital was noted at time 0 min for the optimized film F3. As dissolution time progressed to the first minute, film appeared porous. After 1 min the surface morphology of films showed significant changes in texture, to the extent that the film developed clearly visible pores with solubilization of phenobarbital crystals. SM of pure drug was also taken and it showed crystalline nature of phenobarbital.

Stability studies

F3 formulation was selected for stability studies on the basis of high cumulative $\%$ drug release and also results of in vitro disintegration time. From these results it was concluded 


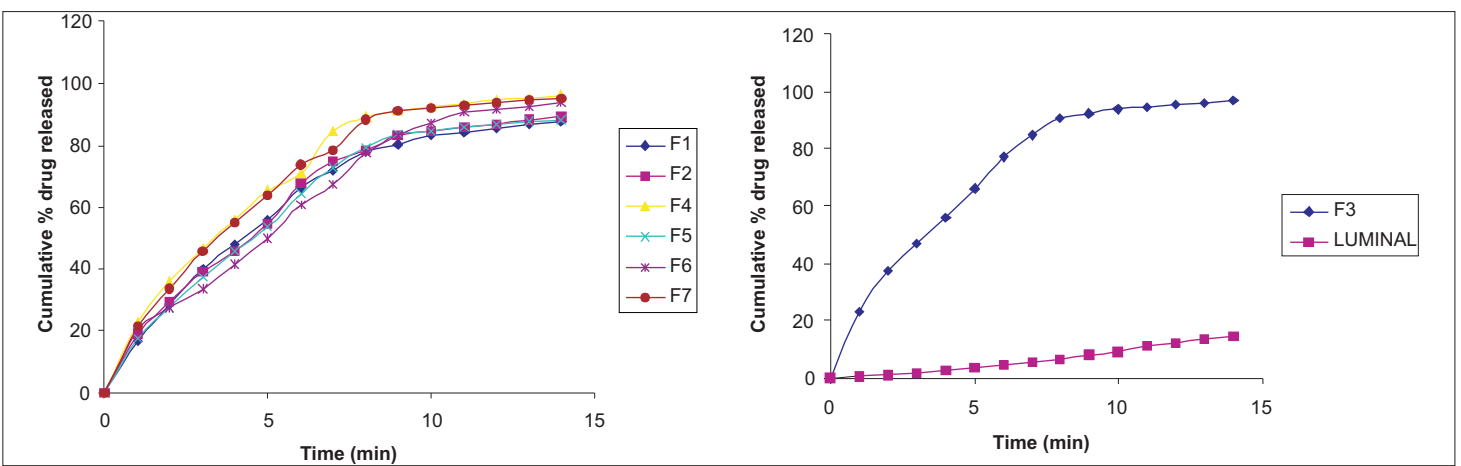

Figure 1: (a) In vitro release profile of phenobarbital mouth dissolving film formulations F1, F2, and F4-F7 (b) In vitro release profile of phenobarbital mouth-dissolving film formulation F3 and LUMINAL
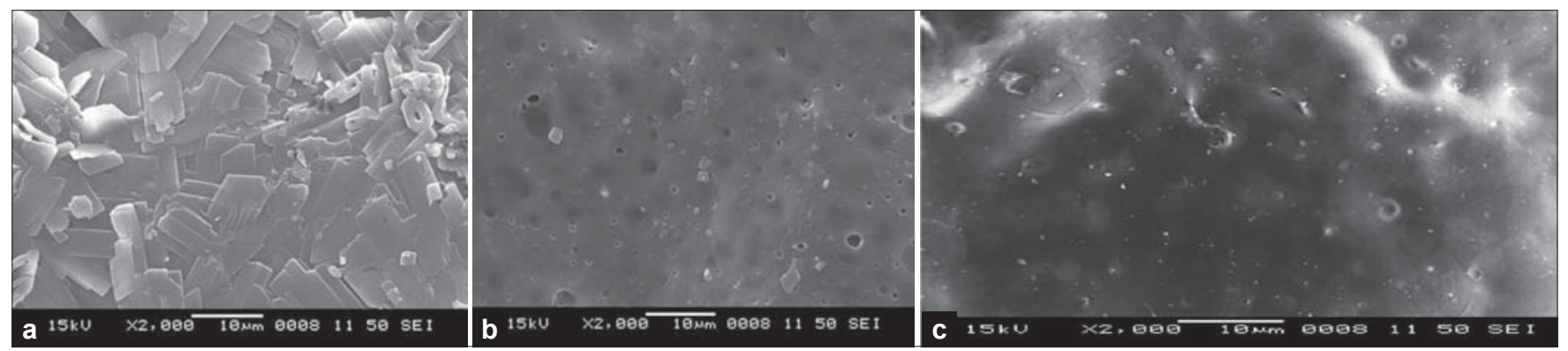

Figure 2: Scanning electron microscope image of (a) pure phenobarbital, (b) formulation F3 at $t=0$ min, (c) formulation F3 at $t=1$ min

Table 5: Model fitting of the release profile using five different models ( $R$ value)

\begin{tabular}{lcccc}
\hline Formulation & \multicolumn{4}{c}{ Mathematical models (Kinetics) } \\
\cline { 2 - 5 } Fode & 0.882 & 0.978 & 0.912 & First order \\
F1 & 0.885 & 0.961 & 0.927 & First order \\
F3 & 0.844 & 0.974 & 0.891 & First order \\
F4 & 0.855 & 0.979 & 0.901 & First order \\
F5 & 0.890 & 0.955 & 0.927 & First order \\
F6 & 0.939 & 0.979 & 0.952 & First order \\
F7 & 0.862 & 0.971 & 0.887 & First order \\
\hline
\end{tabular}

that, formulations F3 is stable and retained their original properties with minor differences. The in vitro release profile of $\mathrm{F} 3$ at $30^{\circ} \mathrm{C} / 60 \% \mathrm{RH}$ and $40^{\circ} \mathrm{C} / 75 \% \mathrm{RH}$ conditions after 30 days was $95.114 \%$ and $92.316 \%$, respectively, has indicated that no or minor alteration after storage.

In vivo animal safety study (irritation study)

The in vivo animal safety study is carried out to ensure safe use of films in oral cavity. Hamster cheek pouch was selected as model for study. Images of cheek pouch area were taken before and after placing of the films. The observation of images obtained of cheek pouch area of hamster before and after placing film shows no irritation or redness. Therefore, F3 formulation has shown good acceptability for oral use in treatment of epileptic attack or seizures. Obtained results have been shown in Figure 3 ( $a$ and $b$ ).

\section{CONCLUSIONS}

Mouth dissolving films of Phenobarbital could be formulated with available low viscosity film formers viz. HPMC E15, Pectin, HPC, Xanthan gum. Phenobarbital, a poorly water soluble drug could be successfully incorporated in mouth dissolving film with the help of propylene glycol as solubilizer and plasticizer. In the present study successful optimization was done to study the influence of film formers, film modifier, plasticizers and superdisintegrants (SDs) in mouth dissolving films. Use of plasticizers in combination could give better results to films in respect to physicochemical parameter, such as tensile strength, \%elongation, folding endurance and flexibility. Incorporation of superdisintegrants in the mouth dissolving film could be useful for rapid disintegration and dissolution time. Amongst all the developed formulations, phenobarbital mouth-dissolving film formulated using sodium starch glycolate (SSC) as superdisintegrant in concentration range of $1 \%(\mathrm{w} / \mathrm{v})$, showed good in vitro disintegration and dissolution time.

In comparison with available marketed formulation, it has found that formulated films showed improved dissolution.

The in vitro drug release, in vitro stability evaluation and physicochemical/mechanical results obtained in this work, confirm the potentials of the mouth dissolving film of phenobarbital as a promising candidate for quick relief from epileptic seizures and attacks with better patient 


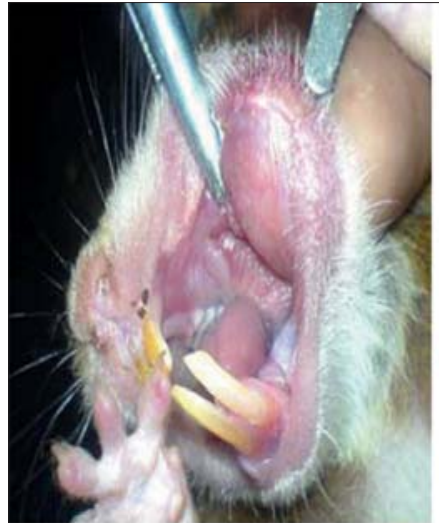

Before placing film

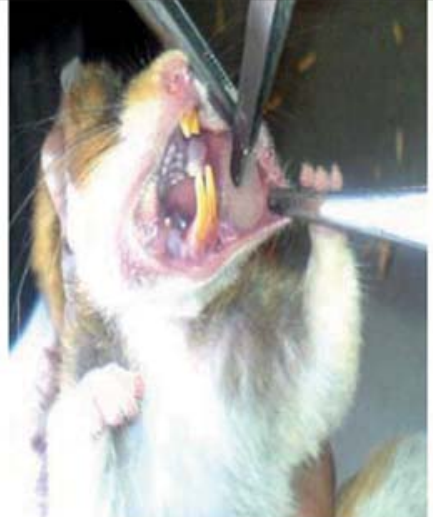

During film placing

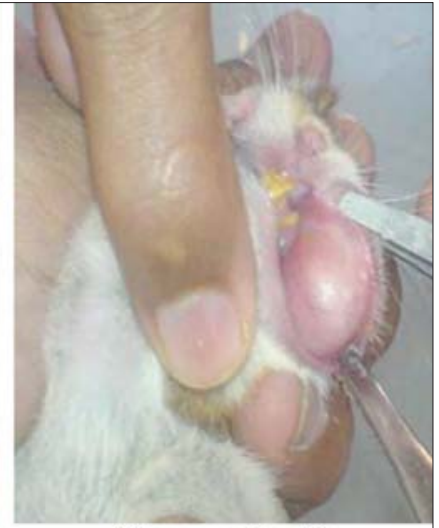

After removing film

Figure 3a: Placebo film safety study on hamsters



Before film placing

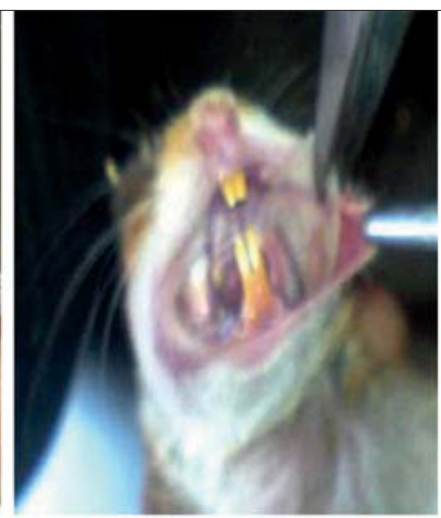

During film placing

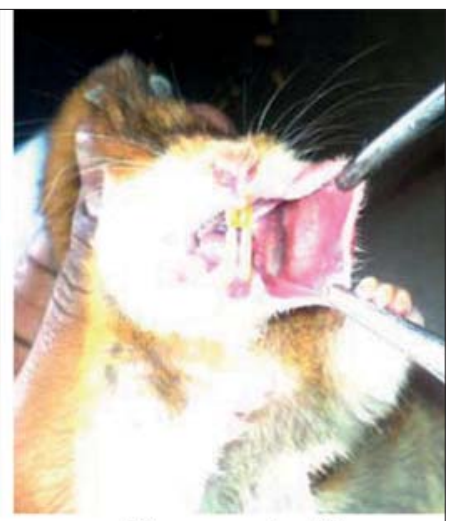

After removing film

Figure 3b: PBT F3 optimized film safety study on hamsters

compliance, with all class of patients. From the in vivo animal safety studies, it was concluded that the optimized formulation had no irritation or redness on cheek pouch area of hamster and had good acceptability for oral use in treatment of epileptic attack or seizures.

\section{REFERENCES}

1. Mishra R, Amin A. Quick API delivery. Pharmaceutical Technology Europe. 2007. Available from: http://www.ptemag.com/pharmtecheurope/ Dosage+Forms/Quick-API delivery/ArticleStandard/Article/detail/4643 14? contextCategoryId $=39142$. [last cited on 2008 July 14].

2. James OM. Drugs effective in the therapy of the epilepsies. In: Hardman JG, Limbrid LE, Goodman G, editors. Goodman and Gilman's 'The Pharmacological Basis of Therapeutics. USA: McGraw Hill; 2001. p. 521-31.

3. Daniel HL. Seizures and Epilepsy. In: K asper DL, Braunwald E, Fauci AS, Hauser SL, editors. Harrison's principle of internal medicine. USA: The McGraw-Hill Companies; 2005. p. 2357.

4. Dinge A, Nagarsenker M. Formulation and evaluation of fast dissolving films for delivery of triclosan to the oral cavity. AAPS Pharm Sci Tech 2008;9:349-56.

5. Swamy NG, Dharmarajan TS, Paranjothi KL. Study of film forming properties of hydroxy propyl guar and its use in preparation of medicated transdermal patches. Indian J Pharm Educ Res 2008;42:147-53.
6. Sharma R, Parikh KA, Gohel MC, Soniwala MM. Development of taste masked film of valdecoxib for oral use. Indian J Pharm Sci 2007;69:320-3.

7. Jin WY, Dharmala K, Chi H. The physicochemical properties of muccoadhesive polymeric films developed as female controlled drug delivery system. Int J Pharm 2006;309:139-45.

8. Tanwar YS, Chauhan CS, Sharma A. Development and evaluation of carvedilol transdermal patches. Acta Pharm 2007;57:151-9.

9. Perumal VA, Lutchman D, Mackraj I, Govender T. Formulation of monolayered films with drug and polymers of opposing solubilities. Int J Pharm 2008;358:184-91.

10. Peh KK, Wong CF. Polymeric films as vehicle for buccal delivery: Swelling, mechanical, and bioadhesive properties. J Pharm Pharm Sci 1999;2:53-61.

11. Agarwal GP, Seth AK, Saini TR. Evaluation of free films. Indian Drugs 1985;23:45-7.

12. Patel R, Naik S, Patel J, Baria A. Formulation Development and evaluation of mouth melting film of ondansetron. Arch Pharm Sci Res 2009;1:212-7.

13. Cilurzo F, Cupone IE, Minghetti P, Selmin F, Montanari L. Fast dissolving films made of maltodextrins. Eur J Pharm Biopharm 2008;70:895-900.

14. Borsadia SB, O'halloran D, Osborne JL. Quick dissolving films-A novel approach to drug delivery. Drug Deliv Technol 2003;3:63-6.

How to cite this article: Yellanki SK, Jagtap S, Masareddy R. Dissofilm: A novel approach for delivery of phenobarbital; design and characterization. J Young Pharmacists 2011;3:181-8.

Source of Support: Nil, Conflict of Interest: None declared. 